\title{
Craniocervical flexion performance in computer users: An observational study
}

\author{
Ashmita Iora Davania Patrao ${ }^{1}$, Stephanie M Correa ${ }^{2}$, Prachi Prakash Kerkar ${ }^{3}$, Kavitha Vishal ${ }^{4}$ \\ ${ }^{1}$ Department of Physiotherapy, Father Muller College of Allied Health Sciences, Mangalore, India; ${ }^{2}$ Department of \\ Rehabilitation, Indiana University Health Hospital, Frankfort, IN, USA; ${ }^{3}$ Department of Community Medicine, Seth GS \\ Medical College and KEM Hospital, Mumbai, India; ${ }^{4}$ Department of Physiotherapy, Manipal College of Health Professions, \\ Manipal Academy of Higher Education, Manipal India
}

\begin{abstract}
Study aim: To compare the performance of deep cervical flexors (DCF) among computer users (CU) and non-users using the craniocervical flexion test (CCFT).

Material and methods: Eighty nine computer users and 100 non-users were recruited for evaluation of their craniocervical muscle performance. The activation score and performance index were assessed using the CCFT. Comparison of craniocervical flexor performance between the two groups was evaluated using the Mann Whitney test. A Chi-Square test was used to test the association between age, years of work and craniocervical flexion. Significance was set at $\mathrm{p} \leq 0.05$.

Results: The median activation score was lower among computer users (median pressure-24 mmHg as compared to non-users (median pressure-28 mmHg) ( $\mathrm{p}<0.01)$. The performance index among computer users was lower when compared to nonusers. Also, age $(\mathrm{p}<0.001)$ and the years of work experience $(\mathrm{p}=0.006)$ were associated with the DCF performance.

Conclusion: $\mathrm{CU}$ have lower activation and endurance of the DCF compared to non-users. The endurance of the DCF was associated with the age and years of computer usage.
\end{abstract}

\section{Keywords: Deep cervical flexors - Craniocervical flexion test - Work related musculoskeletal disorders - Neck pain}

\section{Introduction}

A good posture is one in which all the body parts are maintained and aligned equally from the midline $[8,12,43]$. Minute alterations or deviations from this posture can increase the stress on the supporting structures $[22,47]$. A forward head posture (FHP) is one such deviation of posture in which the head is relatively anterior to the trunk $[34,35,40,56]$. It presents as an anterior translation of the cervical vertebrae with a hyperextended upper cervical spine [33]. It includes an upper cervical extension with or without lower cervical flexion [49] and tends to cause increased stress on the surrounding structures [20].

FHP is common among computer users $(\mathrm{CU})$ and occurs due to constant gazing at the computer screen [20, 48, 49]. A cervical posture into extension was the most prominent postural deviation noted in this population [7, 57]. As the task of computer usage demands constant sitting, positions have to be maintained for long hours $[11,55]$. Different sitting postures influence the head on neck posture and cervical muscle activity [9]. Prolonged sitting leads to a non-neutral position of the spine, causing low levels of constant muscle activation, thus increasing the spinal loading and reducing the spinal mobility $[1,44,48]$.

An altered neck posture adversely affects the muscle recruitment and movement patterns of the cervical muscles $[11,16]$. An FHP causes the increased thickness of the neck muscles, including the sternocleidomastoid, possibly suggesting increased activation of the superficial muscle [5]. The superficial muscles flex the lower cervical spine and have a different role compared to the deep cervical flexors [54]. The deep cervical flexors, including the longus coli, longus capitus, rectus capitus anterior, and lateralis, have a primary function of flexion of the upper cervical spine while supporting the motion segments of the cervical spine [38]. They are also important stabilizers of the head on neck posture [17]. 
Altered muscle recruitment patterns are associated with the development of symptoms in CUs with the mean activation of the cervical extensors compared with the flexors being more $[4,5]$. This cervical extension predisposes a computer user to develop upper extremity and neck symptoms $[8,41]$. The extent and direction to which the spine posture is altered directly increase the chances for developing upper extremity and neck symptoms in individuals using computers [7]. Studies in the past have established the importance of the deep cervical flexors in the maintenance of neck posture and neck stability $[38,54]$. However, to our knowledge, no study has quantified the strength of craniocervical flexors in CU. Hence the present study aimed to quantify the strength and endurance of craniocervical flexors in CU and control group using the craniocervical flexion test. We hypothesized that a lesser ability to perform the test would give evidence of the sign of impairment of craniocervical flexion in this population.

\section{Materials and methods}

The study protocol was approved by the Institutional Ethics Committee (IEC), Father Muller Medical College Hospital, Mangalore, India. A convenient sample of 189 participants with and without defined hours of computer use were recruited. All participants were provided detailed information about the study procedures and signed written informed consent. CU from two information technology centres in Mangalore, Karnataka, India, were contacted through emails, posters, and advertisements. The employees who were willing to participate in the study and who fulfilled the inclusion criteria were recruited.
We defined computer user as an individual with no history of neck pain and a minimum of one year experience of computer use for a frequency of more than 15 hours per week [18]. The control group which consisted of participants with no history of neck pain were recruited from the local community through word of mouth and advertisements. Exclusion criteria for both the groups included (1) history of neck or shoulder pain for the last two years, (2) pain on palpation of the cervical region, (3) cervical, thoracic or shoulder surgeries (4) associated pain like headaches and TMJ (temporomandibular joint) dysfunction. A physiotherapist with clinical experience in the testing procedures performed the evaluations. Participant demographics included age, and for $\mathrm{CU}$, the duration of work and years of work were noted down.

Craniocervical flexion test: The neuromotor control of the DCF was assessed using the CCFT [29]. Its validity and reliability has been established in symptomatic as well as asymptomatic subjects $[2,23,27,31]$. Furthermore, a systematic review by de Araujo in 2020, establishes its reliability and validity as an assessment tool [13]. This clinical test is based on the activation and isometric endurance of the deep cervical flexor muscles. A pressure biofeedback unit (Chattanooga Group, USA) was used to perform this test. With the participant in supine crook lying position, the pressure bag was placed under the suboccipital area, and the cuff was inflated to $20 \mathrm{mmHg}$, which is the baseline pressure for testing the deep cervical flexors [28]. Before the test commenced, the participants were familiarized with the test procedures. The experiment began with each participant performing a nodding movement like saying "yes" for five incremental stages $(22 \mathrm{mmHg}, 24 \mathrm{mmHg}, 26 \mathrm{mmHg}$, $28 \mathrm{mmHg}, 30 \mathrm{mmHg}$ ) of increasing range and held at each stage for 10 seconds. The time was electronically monitored using a stopwatch, as depicted in figure 1 . The examiner

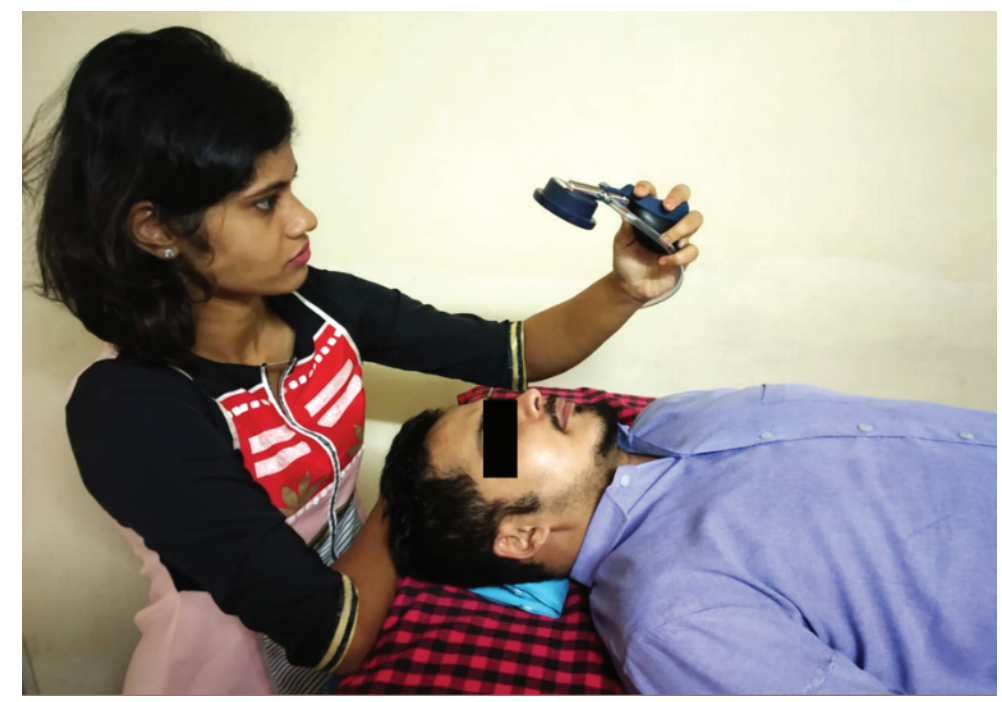

Figure 1. Performance of the Craniocervical flexion test. The participant was in supine lying and performed incremental 5 stages of craniocervical flexion. The pressure cuff was inflated and placed under the suboccipital region 
observed any trick movements that included excessive tucking of the chin or the activation of superficial cervical flexors during the procedure. A 30 second rest period was given after each stage.

The participant has to hold the neck isometrically in 5 increments of upper cervical flexion ('yes' like nod). The activation score was determined as the highest pressure level the participant achieved and held for 10 seconds. When the participant was unable to hold the position at a particular pressure for 10 seconds, the lower value was considered the activation score. [29]. The performance index, is a measure of the endurance of the DCF. Once the activation score is attained, the subject is asked to maintain that pressure level for a duration of 10 seconds. The number of times the participant maintains the activation score out of a maximum of 10 repetitions is the performance index. This was calculated by multiplying the pressure level achieved by the number of time the pressure was held and was considered as the endurance. [1, 23, 27, 29, $31,42]$. The activation score is indicative of the neuromotor activation of the DCF, while the performance index referred to the muscles endurance. Higher values (expressed in $\mathrm{mmHG}$ ) indicate better neuromotor performance in terms of muscle activation and endurance [29].

\section{Statistical analysis:}

Statistical analysis was performed by SPSS version 16 . Demographic characteristics were summarized using descriptive statistics. Baseline comparisons of age between the groups were made using an independent sample t-test. Continuous data were reported using mean and standard deviations (SD). Performance index was expressed as median and interquartile ranges (IQR). The number of individuals that achieved a particular pressure level and held it for 10 seconds was considered for the analysis. A comparison CCFT scores between computer users and non - users was detected by a Mann Whitney U test. A Chi-square test was used to identify the relationship between the demographics and the activation and performance scores. Significance value was set at $\mathrm{p} \leq 0.05$

\section{Results}

Table 1 depicts the demographic characteristics of the participants. 189 participants, 89 computer users and 100 controls participated. They had an average work experience of $4.84 \pm 2.61$ years, and their working hours per day averaged around 9 hours. The performance of the deep cervical flexors from the CCFT test was determined from the activation score and performance index (Table 2). The activation score showed significant difference between $\mathrm{CU}$ and the control group. The target pressure achieved was higher in the control group in comparison to the $\mathrm{CU}$ group.

The median performance index of the computer user group was 20 (IQR-12-30) as compared to 48 in the control group (IQR-40-56), $(\mathrm{p}=0.028)$, as shown in Fig 2. Table 3 depicts the median activation score and

Table 1. Demographic characteristics of the participants $(n=189)$

\begin{tabular}{lcc}
\hline & Computer users $(\mathrm{n}=89)$ & Non-users $(\mathrm{n}=100)$ \\
\hline Age in years $($ mean $\pm \mathrm{SD})$ & $26.60 \pm 2.65$ & $25.4 \pm 2.64$ \\
Gender $(\mathrm{M} / \mathrm{F})$ & $43 / 46$ & $52 / 48$ \\
Years of work $($ mean $\pm \mathrm{SD})$ & $4.84 \pm 2.61$ & - \\
Hours of work $($ mean $\pm \mathrm{SD})$ & $9.19 \pm 8.49$ & - \\
\hline
\end{tabular}

SD - standard deviation, M-males, F-females.

Table 2. Craniocervical muscle performance among participants (activation score and performance index)

\begin{tabular}{lccc}
\hline Target pressure $[\mathrm{mmHg}]$ & Computer user $(\mathrm{n}=89)$ & Non users $(\mathrm{n}=100)$ & $\mathrm{p}$-value \\
\hline 22 & 17 & - & $<$ \\
24 & 33 & 15 & $<0.001^{*}$ \\
26 & 31 & 52 \\
28 & 8 & 32 \\
30 & - & & \\
\hline
\end{tabular}




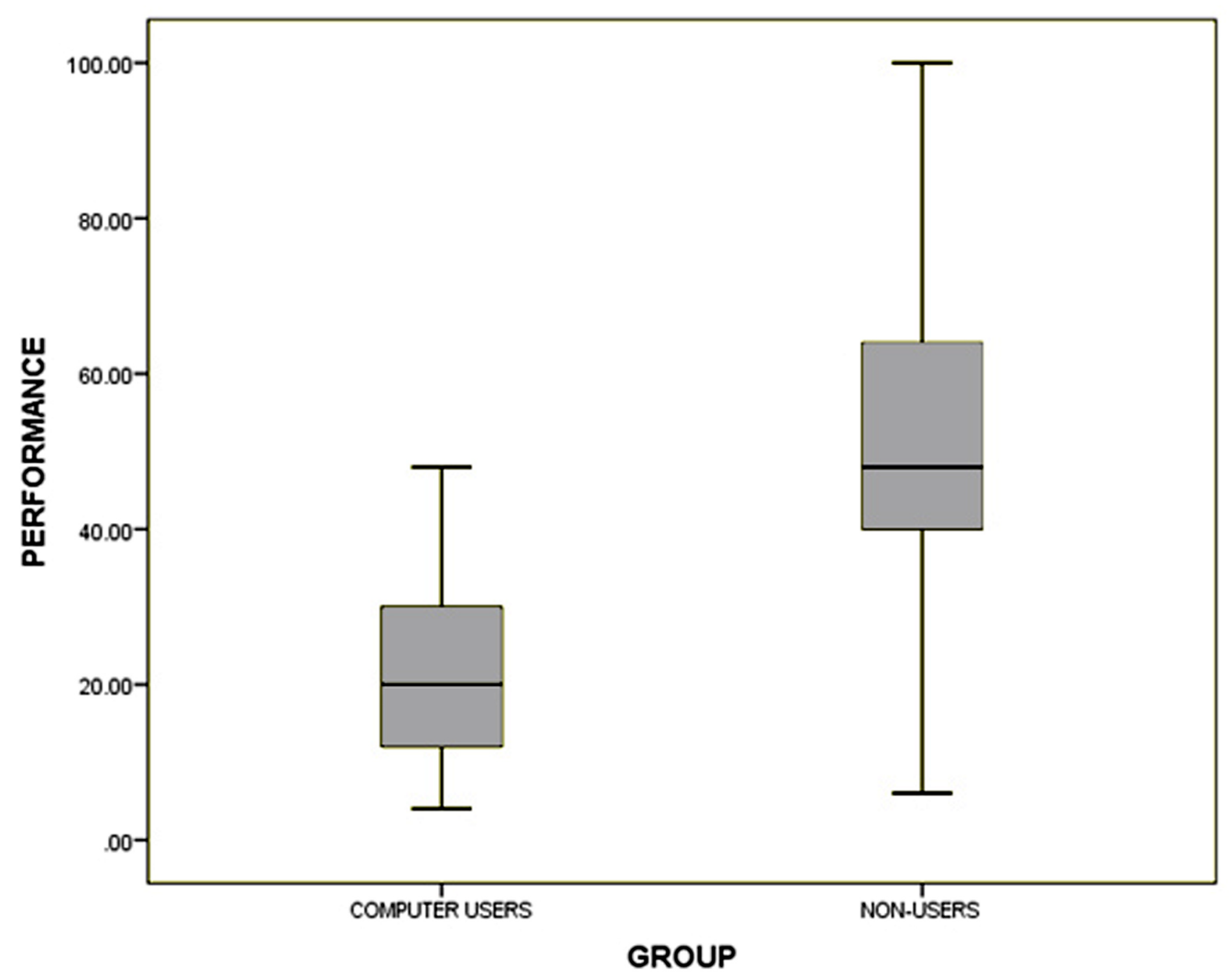

Figure 2. Comparison of performance index between computer users and non- users

Table 3. Age and gender wise distribution of Craniocervical flexion performance (activation score and performance index)

\begin{tabular}{llcccccc}
\hline \multicolumn{1}{c}{} & \multicolumn{2}{c}{ Computer user } & \multicolumn{2}{c}{ Non users } \\
\hline $\begin{array}{l}\text { Age } \\
\text { [years] }\end{array}$ & Gender & $\begin{array}{c}\text { Count } \\
\text { N=89 }\end{array}$ & $\begin{array}{c}\text { Activation score } \\
\text { Median (IQR) }\end{array}$ & $\begin{array}{c}\text { Performance index } \\
\text { Median (IQR) }\end{array}$ & $\begin{array}{c}\text { Count } \\
\text { N=100 }\end{array}$ & $\begin{array}{c}\text { Activation score } \\
\text { Median (IQR) }\end{array}$ & $\begin{array}{c}\text { Performance index } \\
\text { Median (IQR) }\end{array}$ \\
\hline \multirow{2}{*}{$20-25$} & Female & 25 & $6(4-6)$ & $24(12-32)$ & 25 & $8(8-8)$ & $48(40-64)$ \\
& Male & 19 & $4(4-6)$ & $20(16-24)$ & 26 & $10(8-10)$ & $56(46.50-70.5)$ \\
$26-30$ & Female & 20 & $4(2.50-6)$ & $18(16-30)$ & 23 & $8(8-8)$ & $48(36-64)$ \\
& Male & 25 & $4(4-6)$ & $20(11-32)$ & 26 & $8(8-10)$ & $48(40-70.5)$ \\
\hline
\end{tabular}

$\mathrm{N}=$ Total number of subjects; IQR-interquartile range.

performance index, age and gender wise. The relation between the performance index and age was highly significant, $X^{2}(112, N=89)=180.394, p<0.001$. This indicates that the DCF endurance was dependant on the age. Also, the relation between the years of work experience and the performance index was significant, $X^{2}(196, N=89)=249.8, p=0.006$

\section{Discussion}

This study aimed at identifying and understanding the performance of the deep cervical flexors between $\mathrm{CU}$ and non-users. It is based on the anatomical action of the deep cervical flexors, against the pressure biofeedback. This is a simple, reliable clinical test for assessing the cervical spine's muscle impairments requiring minimal instrumentation $[1,23,24]$. These deep cervical flexors, mainly the longus capitus and longus colli, have an anatomical action of reducing the cervical lordotic curve [38, 39].

Our study revealed that the activation score of the deep cervical flexors by the computer users was significantly less than that of the control group. This establishes our hypothesis of prolonged sitting and constant neck postures affecting the activation of the neck core muscles. The possible mechanism for this has been explained in similar 
studies wherein the postural neck muscles demonstrate an increased muscle activation. Jull and Falla, in their study, affirmed the inverse relationship between the superficial neck flexors and DCF, as, with increased activation of the superficial neck muscles, there was a reduced activation of the DCF [30]. This could indicate the presence of altered muscle activation strategies. Studies suggest that physically stressful work conditions increase the electromyography activity in the postural neck muscles [50]. It has even been established in computer users that there is an increased motor response as the psychological work stressors increase. However, this response was noted in the superficial neck muscles [53]. We assume that the altered muscle strategies due to prolonged static postures cause this change. Similar studies have also explained some motor mechanisms associated with increased activation of the postural muscles, even in asymptomatic computer users [48-50]. A similar compensatory strategy must have occurred in our group of computer users. However, compensatory strategies vary from subject to subject [19].

In our study, age showed no association with the activation score but showed a significant association with the performance index $(p<0.001)$. When performed on adolescent and young adults, a similar association of age and muscle performance was identified [25]. However, some studies found age having no association with the neck muscle performance [32]. There was no association with gender and the performance of the DCF in our study. These findings are similar to those previously established, indicating no influence of gender on the performance in the CCFT test [10, 31]. Years of work was also associated with cervical muscle performance. This could be due to maintaining constant postures which may cause an enhanced coactivation of the supporting muscles, and has been supported by studies associating more work hours at the computer with the development of musculoskeletal pain [45].

Several authors have identified neck muscle impairments in neck pain patients $[10,15,26]$ and the effect of strengthening the DCF on neck pain $[3,4,6,21,28,51]$. However, to our knowledge, this is the first study to quantify the neck muscle performance in the asymptomatic population of an ergonomically vulnerable group. Our results identify cervical muscle impairment in computer users that may predispose an individual to neck dysfunction. Also, the reduced performance index suggests decreased deep cervical flexor endurance. It can be hypothesized that $\mathrm{CU}$ adopt a posture of cervical extension, which may reduce the activation of the deep cervical flexors [41].

Exercises are considered as a primary intervention for patients with neck pain $[21,46]$. Studies demonstrate the effectiveness of cervical motor control training in individuals with neck pain $[14,37,52]$. The results of this study can be used as a basis for exercise prescription to improve DCF performance as an ergonomic intervention for all employees exposed to computers for a long duration of time. The strengthening of DCF has been proven effective in reducing disability and symptoms of the neck and upper extremity, which can also correct the neck slope angle $[10,16]$. Longitudinal studies may explore the effectiveness of cervical motor control training in preventing neck pain in individuals using visual display units.

Future studies could screen computer users at regular intervals in order to identify impairments in posture and deep cervical performance. Since our study was a one time evaluation and suggests weakness of the DCF a regular screening is warranted.

\section{Limitations}

We did not perform a sample size calculation. However, we feel that our number was sufficient to be able to explore our hypothesis. Our population consisted of users who were young. Hence we cannot generalize our results to an aging population. We did not measure superficial muscle activity during CCFT using electromyography. This could have affected our results. However, we feel that CCFT is an excellent clinical method to assess the performance of the craniocervical flexors objectively.

\section{Conclusion}

Computer users have lower activation and performance of the deep cervical flexors compared to non-users. Additionally, the age and years of work experience affected muscle endurance in this population. The study findings pave the way for a potential role in strengthening the cervical muscles in an asymptomatic population of computer users.

\section{Conflict of interest: Authors state no conflict of interest.}

\section{References}

1. Ahmed Iqbal Z., Rajan R., Ahmed Khan S., Alghadir A.H. (2013) Effect of deep cervical flexor muscles training using pressure biofeedback on pain and disability of school teachers with neck pain. J. Phys. Ther. Sci., 25(6): 657-661. DOI: 10.1589/jpts.25.657.

2. Arumugam A., Mani R., Raja K. (2011) Interrater reliability of the craniocervical flexion test in asymptomatic individuals - A cross-sectional study. J. Manipulative Physiol. Ther., 34(4): 247-253. DOI: 10.1016/j. jmpt.2011.04.011.

3. Beer A., Treleaven J., Jull G. (2012) Can a functional postural exercise improve performance in the cranio-cervical flexion test? - A preliminary study. Man. Ther., 17(3): 219-224. DOI: 10.1016/j.math.2011.12.005. 
4. Bokaee F., Rezasoltani A., Manshadi F.D., Naimi S.S., Baghban A.A., Azimi H. (2017) Comparison of cervical muscle thickness between asymptomatic women with and without forward head. Braz. J. Phys. Ther., 21(3): 206-211. DOI: 10.1016/j.bjpt.2017.04.003.

5. Bokaee F., Rezasoltani A., Manshadi F.D., Naimi S.S., Baghban A.A., Azimi H. (2016) Comparison of isometric force of the craniocervical flexor and extensor muscles between women with and without forward head posture. Cranio-J. Craniomandib. Pract., 34(5): 286-290. DOI: 10.1080/08869634.2016.1169616.

6. Brage K., Ris I., Falla D., Søgaard K., Juul-Kristensen B. (2015) Pain education combined with neck - and aerobic training is more effective at relieving chronic neck pain than pain education alone - A preliminary randomized controlled trial. Man Ther., 20(5): 686-693. DOI: 10.1016/j.math.2015.06.003.

7. Brink Y., Louw Q., Grimmer K. (2018) The amount of postural change experienced by adolescent computer users developing seated -related upper quadrant musculoskeletal pain. J. Bodyw. Mov. Ther., 22(3): 608-617. DOI: 10.1016/j.jbmt.2017.10.002.

8. Brink Y., Louw Q., Grimmer K., Schreve K., Westhuizen G. Van Der. (2013) Development of a cost effective three-dimensional posture analysis tool: validity and reliability. BMC Musculoskelet Disord., 14: 335. DOI: 10.1186/1471-2474-14-335.

9. Caneiro J., Sullivan P.O., Burnett A., Barach A., Neil D.O., Tveit O., Olafsdottir K. (2010) The influence of different sitting postures on head / neck posture and muscle activity. Man Ther., 15(1): 54-60. DOI: 10.1016/j. math.2009.06.002.

10. Chiu T.T.W., Law E.Y.H., Chiu T.H.F. (2005) Performance of the craniocervical flexion test in subjects with and without chronic neck pain. J. Orthop. Sports Phys. Ther., 35(9): 567-571. DOI: 10.2519/jospt.2005.35.9.567.

11. Ciccarelli M., Straker L., Mathiassen S.E., Pollock C. (2014) Posture variation among office workers when using different information and communication technologies at work and away from work. Ergonomics, 57(11): 1678-1686. DOI: 10.1080/00140139.2014.945493.

12. Claus A.P., Hides J.A., Moseley G.L., Hodges P.W. (2009) Different ways to balance the spine: Subtle changes in sagittal spinal curves affect regional muscle activity. Spine (Phila Pa 1976), 34(6): 208-214. DOI: 10.1097/ BRS.0b013e3181908ead.

13. de Araujo F.X., Ferreira G.E., Schell M.S., de Castro M.P., Ribeiro D.C., Silva M.F.(2020) Measurement Properties of the Craniocervical Flexion Test: A Systematic Review. Phys Ther., 100(7): 1094-1117. DOI: 10.1093/ ptj/pzaa072.

14. Dusunceli Y., Ozturk C., Atamaz F., Hepguler S., Durmaz B. (2009 ) Efficacy of neck stabilization exercises for neck pain: A randomized controlled study. J. Rehabil. Med., 41(8): 626-631. DOI: 10.2340/16501977-0392.

15. Elsig S., Luomajoki H., Sattelmayer M., Taeymans J., Tal-Akabi A., Hilfiker R. (2014) Sensorimotor tests, such as movement control and laterality judgment accuracy, in persons with recurrent neck pain and controls. A case-control study. Man. Ther., 19(6): 555-561. DOI: 10.1016/j.math.2014.05.014.

16. Falla D., Jull G., Russell T., Vicenzino B., Hodges P. (2007) Effect of Neck Exercise on Sitting Posture in Patients with Chronic Neck Pain. Phys Ther., 87(4): 408-417. DOI: 10.2522/ptj.20060009.

17. Falla D.L., Jull G.A., Hodges P.W. (2004) Patients with neck pain demonstrate reduced electromyographic activity of the deep cervical flexor muscles during performance of the craniocervical flexion test. Spine (Phila Pa 1976), 29(19): 2108-2114. DOI: 10.1097/01. brs.0000141170.89317.0e.

18. Gerr F., Marcus M., Ensor C., Kleinbaum D., Cohen S., Edwards A., Gentry E., Ortiz D.J., Monteilh C. (2002) A prospective study of computer users: I. Study design and incidence of musculoskeletal symptoms and disorders. Am. J. Ind. Med., 41(4): 221-235. DOI: 10.1002/ ajim. 10066.

19. Gizzi L., Muceli S., Petzke F., Falla D. (2015) Experimental muscle pain impairs the synergistic modular control of neck muscles. PLoS One, 10(9): 1-19. DOI:10.1371/ journal.pone.0137844.

20. Grimmer K. (1997) An investigation of poor cervical resting posture. Aust. J. Physiother., 43(1): 7-16. DOI: 10.1016/s0004-9514(14)60398-6.

21. Gross A.R., Paquin J.P., Dupont G., Blanchette S., Lalonde P., Cristie T., Graham N., Kay T.M., Burnie S.J., Gelley G., Goldsmith C.H. (2016) Exercises for mechanical neck disorders: A Cochrane review update. Man. Ther., 24: 25-45. DOI: 10.1016/j.math.2016.04.005.

22. Harms-Ringdahl K., Ekholm J., Schüldt K., Németh G., Arborelius U.P. (1986) Load moments and myoelectric activity when the cervical spine is held in full flexion and extension. Ergonomics, 29(12): 1539-1552. DOI: $10.1080 / 00140138608967267$.

23. Hudswell S., Von Mengersen M., Lucas N. (2005) The cranio-cervical flexion test using pressure biofeedback: A useful measure of cervical dysfunction in the clinical setting? Int. J. Osteopath. Med., 8(3): 98-105. DOI: 10.1016/j.ijosm.2005.07.003.

24. James G., Doe T. (2010) The craniocervical flexion test: intra-tester reliability in asymptomatic subjects. Physiother. Res. Int., 15(3): 144-149. DOI: 10.1002/pri.456.

25. Jarman N.F., Brooks T., James C.R., Hooper T., Wilhelm M., Brisme J., Domenech M.A., Kotara S.J., Sizer P.S. (2017) Deep Neck Flexor Endurance in the Adolescent and Young Adult : Normative Data and Asso- 
ciated Attributes. PM R., 9(10): 969-975. DOI: 10.1016/j. pmrj.2017.02.002.

26. Jesus F.M.R., Ferreira P.H., Ferreira M.L. (2008) Ultrasonographic measurement of neck muscle recruitment: A preliminary investigation. J. Man. Manip. Ther., 16(2): 88-92. DOI: 10.1179/106698108790818486.

27. Jørgensen R., Ris I., Falla D., Juul-Kristensen B. (2014) Reliability, construct and discriminative validity of clinical testing in subjects with and without chronic neck pain. BMC Musculoskelet Disord., 15(1): 1-15.

28. Jull G.A., Falla D., Vicenzino B., Hodges P.W. (2009) The effect of therapeutic exercise on activation of the deep cervical flexor muscles in people with chronic neck pain. Man Ther., 14(6): 696-701. DOI: 10.1016/j. math.2009.05.004.

29. Jull G.A., O’Leary S.P., Falla D.L. (2008) Clinical Assessment of the Deep Cervical Flexor Muscles: The Craniocervical Flexion Test. J. Manipulative Physiol. Ther., 31(7): 525-33. DOI: 10.1016/j.jmpt.2008.08.003.

30. Jull G., Falla D. (2016) Does increased superficial neck flexor activity in the craniocervical flexion test reflect reduced deep flexor activity in people with neck pain? Man. Ther., 25: 43-47. DOI: 10.1016/j.math.2016.05.336.

31. Juul T., Langberg H., Enoch F., Søgaard K. (2013) The intra- and inter-rater reliability of five clinical muscle performance tests in patients with and without neck pain. BMC Musculoskelet Disord., 14: 1-15.

32. Kelly M., Cardy N., Melvin E., Reddin C., Ward C., Wilson F. (2013) The craniocervical flexion test : An investigation of performance in young asymptomatic subjects. Man. Ther., 18(1): 83-86. DOI: 10.1016/j.math.2012.04.008.

33. Kim M.S. (2015) Neck kinematics and sternocleidomastoid muscle activation during neck rotation in subjects with forward head posture. J. Phys. Ther. Sci., 27(11): 3425-3428. DOI: $10.1589 /$ jpts.27.3425.

34. Knott P.T., Mardjetko S.M., Techy F. (2010) The use of the $\mathrm{T} 1$ sagittal angle in predicting overall sagittal balance of the spine. Spine J., 10(11): 994-998. DOI: 10.1016/j. spinee.2010.08.031.

35. Lau K.T., Cheung K.Y., Chan Kwok B., Chan M.H., Lo K.Y., Wing Chiu T.T. (2010) Relationships between sagittal postures of thoracic and cervical spine, presence of neck pain, neck pain severity and disability. Man Ther., 15(5): 457-462. DOI: 10.1016/j.math.2010.03.009.

36. Lin I.H., Chang K.H., Liou T.H., Tsou C.M., Huang Y.C. (2018) Progressive shoulder-neck exercise on cervical muscle functions in middle-aged and senior patients with chronic neck pain. Eur. J. Phys. Rehabil. Med., 54(1): 13-21. DOI: 10.23736/S1973-9087.17.04658-5.

37. Martin-Gomez C., Sestelo-Diaz R., Carrillo-Sanjuan V., Navarro-Santana M.J., Bardon-Romero J., Plaza-Manzano G. (2019) Motor control using cranio-cervical flexion exercises versus other treatments for non-specific chronic neck pain: A systematic review and meta-analysis.
Musculoskelet Sci. Pract., 42: 52-59. DOI: 10.1016/j. msksp.2019.04.010.

38. Mayoux-benhamou M.A., Revel M., Vallee C., Roudier R., Barbet J.P., Bargy F. (1994) Longus colli has a postural function on cervical curvature. Surg. Radiol. Anat., 16: 367-371. DOI: 10.1007/BF01627655.

39. Mayoux-Benharmou M., Revel M., Vallee C. (1997) Selective electromyography of dorsal neck muscles in humans. Exp. Brain Res., 113(2): 353-360. DOI: 10.1007/ BF02450333.

40. McAviney J., Schulz D., Bock R., Harrison D.E., Holland B. (2005) Determining the relationship between cervical lordosis and neck complaints. J. Manipulative Physiol. Ther., 28(3): 187-93. DOI: 10.1016/j. jmpt.2005.02.015.

41. Nejati P., Lofyfian S., Moezy A., Nejati M. (2015) The study of Correlation between Forward Head Posture and Neck Pain. Int. J. Occup. Med. Environ. Health, 28(90): 295-303. DOI: 10.13075/ijomeh.1896.00352.

42. Olson L.E., Millar A.L., Dunker J., Hicks J., Glanz D. (2006) Reliability of a clinical test for deep cervical flexor endurance. J. Manipulative Physiol. Ther., 29(2): 134-138. DOI: 10.1016/j.jmpt.2005.12.009.

43. Ruivo R.M., Pezarat-Correia P., Carita A.I. (2015) Intrarater and interrater reliability of photographic measurement of upper-body standing posture of adolescents. J. Manipulative Physiol. Ther., 38(1): 74-80. DOI: 10.1016/j.jmpt.2014.10.009.

44. Schüldt K., Ekholm J., Harms-Ringdahl K., Németh G., Arborelius U.P. (1986) Effects of changes in sitting work posture on static neck and shoulder muscle activity. Ergonomics, 29(12): 1525-1537. DOI: 10.1080/00140138608967266.

45. Smith L., Louw Q., Crous L., Grimmer-Somers K. (2009) Prevalence of neck pain and headaches: impact of computer use and other associative factors. Cephalalgia, 29(2): 250-257. DOI: 10.1111/j.1468-2982.2008.01714.x.

46. Southerst D., Nordin M.C., Côté P., Shearer H.M., Varatharajan S., Yu H., Wong J.J., Sutton D.A., Randhawa K.A., van der Velde G.M., Mior S.A. (2016) Is exercise effective for the management of neck pain and associated disorders or whiplash-associated disorders? A systematic review by the Ontario Protocol for Traffic Injury Management (OPTIMa) Collaboration. Spine J., 16(12): 1503-1523. DOI: 10.1016/j.spinee.2014.02.014.

47. Straker L., Jones K.J., Miller J. (1997) A comparison of the postures assumed when using laptop computers and desktop computers. Appl. Ergon., 28(4): 263-268. DOI: 10.1016/s0003-6870(96)00073-7

48. Szeto G.P.Y., Straker L.M., Sullivan P.B.O. (2005) A comparison of symptomatic and asymptomatic office workers performing monotonous keyboard work -1 : Neck and shoulder muscle recruitment patterns., Man. Ther., 10: 270-280. DOI: 10.1016/j.math.2005.01.004. 
49. Szeto G.P.Y., Straker L., Raine S. (2002) A field comparison of neck and shoulder postures in symptomatic and asymptomatic office workers. Appl. Ergon., 33(1): 75-84. DOI: 10.1016/s0003-6870(01)00043-6.

50. Szeto G.P.Y., Straker M.L., Sullivan P.B. (2009) Neckshoulder muscle activity in general and task-specific resting postures of symptomatic computer users with chronic neck pain. Man Ther., 14(3): 338-345. DOI: 10.1016/j. math.2008.05.001.

51. Takasaki H., Herbowy S. (2016) Immediate improvement in the cranio-cervical flexion test associated with MDT-based interventions: a case report. J. Man. Manip. Ther., 24(5): 285-292. DOI: 10.1179/2042618614Y.0000000081.

52. Thoomes-De Graaf M., Schmi M.A. (2012) The effect of training the deep cervical flexors on neck pain, neck mobility, and dizziness in a patient with chronic nonspecific neck pain after prolonged bed rest: A case report. J. Orthop. Sports Phys. Ther., 42(10): 853-860. DOI: 10.2519/ jospt.2012.4056.

53. Thorn S., Søgaard K., Kallenberg L.A.C., Sandsjö L., Sjøgaard G., Hermens H.J., Kadefors R., Forman M. (2007) Trapezius muscle rest time during standardised computer work - A comparison of female computer users with and without self-reported neck/shoulder complaints. J. Electromyogr. Kinesiol., 17(4): 420-427. DOI: 10.1016/j.jelekin.2006.04.010.

54. Vasavada A., Li S., Delp S. (1998) Influence of Muscle Morphometry and Moment arms on the Moment-Generating Capacity of the Human Neck Muscles. Spine, 23(4): 412-422. DOI: 10.1097/00007632-199802150-00002.

55. Woo E., White P., Lai C. (2015) Ergonomics Standards and Guidelines for Computer Workstation Design and the Impact on Users ' Health - A Review. Ergonomics, 59(3): 464-475. DOI: 10.1080/00140139.2015.1076528.

56. Yip C.H.T., Chiu T.T.W., Poon A.T.K. (2008) The relationship between head posture and severity and disability of patients with neck pain. Man. Ther., 13(2): 148-154. DOI: 10.1016/j.math.2006.11.002.

57. Yoo W., An D. (2009) The Relationship between the Active Cervical Range of Motion and Changes in Head and Neck Posture after Continuous VDT Work. Ind. Health, 47(2): 183-188. DOI: 10.2486/indhealth.47.183.

\section{Received 24.09.2020 \\ Accepted 09.04.2021}

(C) University of Physical Education, Warsaw, Poland 